\title{
Patients With Hereditary Angioedema Do Not Develop More Severe COVID-19 but SARS-CoV- 2 Infection May Trigger Attacks: 66 Cases
}

\section{Maria Margarita Olivares}

Medellín-Colombia

Ricardo Dario Zwiener

Hospital Universitario Austral. Pilar

Lina Maria Leiva Panqueva

Universidad Surcolombiana

Francisco Alberto Contreras Verduzco

Servicio de Alergia del Instituto Nacional de Pediatría

\section{Eli Mansour}

University of Campinas

Jairo Antonio Rodriguez

Universidad Surcolombiana

\section{Solange Oliveira Rodrigues Valle}

Hospital Universitário Clementino Fraga Filho

\section{Sandra Nieto}

Unidad de Genética de la Nutrición

Jane Da Silva

Federal University of Santa Catarina

\section{Daniel 0 Vazquez}

Servicio de alergia Clínica Privada Monte Grande, Buenos Aires

\section{Oscar Calderon Llosa}

Centro ACARE, Clínica Sanna el Golf

\section{Fernanda Casares Marcelino}

Hospital Regional da Asa Norte-Brasilia

\section{Manuel Ratti-Sisa}

Clinica Cis, Asunción-Paraguay

lleana María Madrigal Beas

Unidad Médica de Alta Especialidad

\section{Rafael Zaragoza-Urdaz}

University of Puerto Rico

Eliana Cristina Toledo 
Faculdade de Medicina de Sao Jose do Rio Preto - São Paulo

\section{Natalia Lorena Fili}

Hospital Público Materno Infantil de Salta

\section{Olga M Barrero}

Instituto de Neumología y Alergias. Ciudad de Panamá- Panamá

\section{Juan Carlos Fernandez de Cordova Aguirre}

Hospital del Instituto Ecuatoriano de Seguridad social. Cuenca

\section{Sergio Castro Mora}

Universidad de Costa Rica

\section{Mauricio Sarrazola}

Universidad de Pamplona

\section{Rodolfo Jaller Raad}

Centro de Asma Alergia e Inmunología CAAI Barranquilla

\section{Edison Morales Cardenas}

Unidad Alergológica

\section{Dario Oscar Josviak}

Instituto de Medicina Respiratoria- Rafaela

Claudio Fantini

Servicio Alergia e Inmunología Clínica Colón

\section{Monica Marocco}

Hospital Aeronáutico de Córdoba

\section{Elma I Nievas}

Hospital Pediátrico A Fleming -OSEP

\section{Faradiba Sarquis Serpa}

Escola Superior de Ciências da Santa Casa de Misericórdia de Vitória

\section{Herberto Jose Chong Neto}

Universidade Federal do Paraná. Brazil

\section{Maria Luiza Oliva Alonso}

Hospital Universitário Clementino Fraga Filho

\section{Sergio Dortas Junior}

Hospital Universitário Clementino Fraga Filho

\section{Raisa Gusso Ulaf}

University of Campinas

\section{Nelson Rosario}

Universidade Federal do Paraná. Brazil

\section{Rodolfo Ramón Leyva Barrero}

Ips megsalud

Anete Sevciovic Grumach ( $\sim$ anete@grumach.com )

Faculdade de Medicina do ABC https://orcid.org/0000-0002-9803-0309 


\section{Research Article}

Keywords: Hereditary angioedema, C1 inhibitor, COVID-19, SARS-CoV-2, Androgen, Risk factor, Trigger, Hereditary angioedema with normal C1-INH

Posted Date: April 7th, 2021

DOI: https://doi.org/10.21203/rs.3.rs-381339/v1

License: (c) (i) This work is licensed under a Creative Commons Attribution 4.0 International License. Read Full License 


\section{Abstract}

\section{Purpose}

Hereditary angioedema (HAE) is a rare genetic disease with hyperactivated contact and kallikrein-kinin systems leading to bradykinin (BK) release and edema. SARS-CoV-2 infection results in inflammatory exacerbation. $\mathrm{C} 1$ inhibitor (C1-INH) deficiency could aggravate clinical outcomes, with HAE patients at a greater risk of adverse outcomes of COVID-19, however, data are still limited. Our aim was to characterize the course and severity of COVID-19 in patients with HAE.

\section{Methods}

Latin American HAE reference centers evaluated SARS-CoV-2 infection in this population. Patients with confirmed diagnosis of HAE with (HAE-C1-INH) or without C1-INH deficiency (HAE-nC1-INH) were included. HAE symptomatology and the course of COVID-19 were characterized with the application of a questionnaire.

Results

66 patients from 10 countries (HAE-C1-INH 80,3\%; HAE-nC1-INH 19.6\%) were reported with SARS-CoV-2 infection. Comorbidities were absent in $69.7 \%$ of the patients and obesity present in $12.1 \%$. Attacks occurred in $45.5 \%$ of patients with HAE during SARS-CoV-2 infection. Long term prophylaxis was reported in 52\% (34/66) of HAE patients. Complete cure was observed in 61 patients (92.4\%), pulmonary sequelae in 4 and death in one HAE-C1-INH patient. The cause of death was septic shock secondary to bacterial pulmonary coinfection. Disease progression was not impacted by sex, therapy or type of HAE $(p=0.803)$.

\section{Conclusion}

Attacks occurred in almost half of HAE patients suggesting that SARS-CoV-2 infection is a trigger. HAE did not represent a risk factor for a worse outcome of COVID-19, even in use of androgens.

\section{Highlights}

Data regarding the course of COVID-19 in HAE patients are still limited. We observed that SARS-CoV-2 infection can trigger attacks in HAE with or without C1-INH deficiency, however, severe disease had a similar incidence in HAE patients.

\section{Introduction}

Hereditary angioedema (HAE) is a rare genetic disease with autosomal dominant inheritance characterized by localized and asymmetric episodes of subcutaneous and submucosal edema with a high impact on quality of life ${ }^{1,2,3}$. Unnecessary surgeries and death due to airway obstruction can occur 2,4 . Two types of HAE are recognized: HAE with deficiency and/or dysfunctional C1 inhibitor (HAE-C1-INH) 
and HAE with normal C1-INH (HAE-nC1-INH); and the estimated prevalence is 1:50,000 and 1:400.000, respectively 4,5 . Gene variants involved with $\mathrm{HAE}-\mathrm{C} 1-\mathrm{INH}$ are identified in SERPING1 gene and variants in genes encoding for coagulation factor XII (F12), Plasminogen, Kininogen 1, Angiopoetin1, Myoferlin and, more recently, heparan sulfate (HS)-glucosamine 3-0-sulfotransferase $6^{6}$ were associated with HAE-nC1$\mathrm{INH}$. There is a cluster of patients with unknown variants within the HAE-nC1-INH group ${ }^{2}$.

The mechanism involved in HAE is the activation of the contact and kallikrein-kinin systems, resulting in the release of bradykinin (BK), after the cleavage of high molecular weight kininogen (HK) by kallikrein. Kallikrein is the active cleaved form of pre-kallikrein formed after cleavage by activated FXII. After release, $\mathrm{BK}$ or its derivative des-Arg9-bradykinin (DABK), binds to B2R or B1R, respectively, generating increased vascular permeability, which causes angioedema. $\mathrm{C} 1-\mathrm{INH}$ inhibits not only contact and kallikrein-kinin systems but also fibrinolytic, complement and coagulation pathways and its deficiency or dysfunction leads to increased BK release. In most HAE-nC1-INH, the same mechanism is observed ${ }^{7,8}$.

The clinical spectrum of COVID-19, the disease caused by SARS-CoV-2, varies widely, from asymptomatic or mild symptoms similar to common colds to severe respiratory failure with risk of death. Recognized risk groups for the severity of the infection are age over 60 , hypertension, diabetes and obesity ${ }^{9}$. Several fatal complications have been observed in the course of the disease: heart, liver or kidney failure, among others ${ }^{9,10}$.

SARS-CoV-2 uses surface proteins to invade host cells. The virus' spike glycoprotein binds to the angiotensin-converting enzyme 2 (ACE2), which is highly expressed on the surface of respiratory cells, and this interaction is considered essential for SARS-CoV-2 to enter target cells. In some cells, the "spike" glycoprotein can bind to other surface proteins, such as TCD $4+$ cells $^{10,11}$. The binding of SARS-CoV-2 causes negative regulation of ACE2, influencing the regulation of the renin-angiotensin system, possibly related to changes in blood pressure and inflammation ${ }^{10}$.

Considering the action of ACE2 inhibitors in the kallikrein-kinin system and the observation that antiinflammatory treatments have limited efficacy in respiratory distress, the relationship between the activated contact and kallikrein-kinin systems and the pulmonary manifestations of COVID-19 is a strong possibility ${ }^{12-15}$. Clinical studies with small number of patients and severe COVID-19 treated with recombinant or plasma-derived $\mathrm{C} 1$ inhibitor, or even icatibant, showed improved clinical, laboratory and radiological parameters ${ }^{12-14}$, reinforcing the role of these systems ${ }^{15}$.

A patient with HAE and COVID-19 has been reported, which manifested a mild illness without triggering an attack of angioedema ${ }^{16}$. In addition, a patient with acquired non-histaminergic angioedema was reported with mild COVID-19 and without angioedema attack ${ }^{17}$. A recent casuistry showed mild disease in HAE patients ${ }^{18}$.

Considering the scarcity of data about hereditary angioedema with or without C1 inhibitor deficiency and COVID-19, we collected clinical characteristics of these patients in a wider population focusing the 
severity and evolution of the infection.

\section{Methods}

HAE Referral Centers in Latin American countries were consulted about patients with SARS-CoV-2 infection. For inclusion in the study, there was no age limit or restriction to risk factors for COVID-19. The diagnosis of HAE was confirmed by typical clinical symptoms, biochemical tests evaluating the dosage and / or function of $\mathrm{C} 1$ inhibitor, family history and for patients with HAE-nC1-INH, whenever possible, F12 variants were evaluated. We registered the tests performed for the confirmation of SARS-CoV-2 infection: PCR, serology and / or rapid test. A questionnaire was distributed to the centers including age, sex, type of HAE, risk factors, variants for HAE-nC1-INH if available, prophylaxis for HAE, COVID-19 symptoms, occurrence of angioedema attacks and therapy used for treating each attack, need for hospitalization, period of symptomatology, evolution and complications. The project was submitted and approved by the Ethics Committee (CAAE: 40745220.0.1001.0082).

\section{Results}

Out of $20 \mathrm{HAE}$ reference centers in Latin America, 6 countries (Chile, El Salvador, Guatemala, Honduras, Uruguay and Venezuela) had no HAE patients with SARS-CoV-2 infection; two countries (Cuba, and Dominican Republic) did not respond to the inquiry and Bolivia has no HAE patients identified. Ten countries contributed to the casuistry: Brazil $(n=25)$; Argentina $(n=11)$; Colombia $(n=11)$; Mexico $(n=9)$; Peru ( $n=3)$; Paraguay ( $n=2)$; Puerto Rico $(n=2)$ and Panama, Ecuador and Costa Rica with one patient each. We report 66 patients (mean age $=39.5 \pm 15.1$ years old; $77.3 \%$ females) with confirmed diagnosis of HAE-C1-INH and HAE-nC1-INH, corresponding to $80.3 \%$ and $19.6 \%$, respectively. Diagnosis of SARSCoV-2 infection was performed by RT-PCR in 41 (62.1\%); serology in 7 (10.5\%); rapid test in 3 (4.5\%); clinical symptomatology in $12(18.2 \%)$ and close contact and symptoms in $3(4.5 \%)$.

Comorbidities were not identified in $69.7 \%$ of the patients, obesity was present in $12.1 \%$, diabetes in $6.0 \%$, arterial hypertension 4.5\%, neoplasms and other conditions in 7.7\%. Median time of disease was 11 (IQR: 7-15) and 10 (IQR 3-15) days in patients with HAE-C1-INH and HAE-nC1-INH, respectively. Complete cure was observed in 61 patients (92.4\%), pulmonary sequelae in 4 and death in one patient (Table 1). The disease progression had no difference in relation to the sex or type of $\operatorname{HAE}(p=0.803)$.

Angioedema attacks occurred in $45.5 \%$ of patients with HAE during SARS-CoV-2 infection, predominantly in HAE-C1-INH (26/53) comparing with HAE-nC1-INH (4/13), however, there was no significant difference ( $p>0.05)$. Attacks affected the following sites: face and tongue in $7 / 66$ (10.6\%); extremities in 12/66 (18.2\%); abdomen in $7 / 66(10.6 \%)$ and larynx in $4 / 66(6.1 \%)$. Discriminating by sex, a significant association was evidenced between the groups $(p=0.030)$, with the attacks occurring mainly in women with HAE-C1-INH during COVID-19. Most of the patients who suffered attacks were not receiving prophylaxis and no association between the occurrence of attacks and the use of prophylaxis was observed $(p=0.648)$. Androgens was used for long term prophylaxis in $48.4 \%$ of the patients $(32 / 66)$, 
among which $93.3 \%$ progressed to cure after suffering SARS-CoV2 infection with no sequelae. Only a 71year-old woman was reported as deceased within this group due to septic shock.

Treatment of the SARS-CoV-2 infection in these patients was based on analgesics and antipyretics in $53 \%$, mainly paracetamol (acetaminophen) (42.4\%), antibiotics in $22.7 \%$, azithromycin being the most used $(18.1 \%)$, followed by anti-inflammatories in $11 \%$. Combined therapies, based on the aforementioned drugs, were utilized by $22.1 \%$ of the cases; and other therapies such as vitamins and ivermectin were prescribed in $7.6 \%$.

\section{Discussion}

The severe acute respiratory syndrome coronavirus 2 (SARS-CoV-2) first emerged in Wuhan (Hubei Province, China), in December 2019, and COVID-19 pandemic has spread rapidly worldwide. Only a small percentage of patients develop the potentially lethal complications of acute respiratory distress syndrome (ARDS), disseminated intravascular coagulation (DIC), and multiorgan failure (MOF) ${ }^{19,20}$. After entering the host, SARS-CoV-2 elicits a series of innate and adaptive immune responses, which are responsible for viral clearance as well as inflammation. Emerging evidences suggest that complement is chronically activated in severe COVID-19 and plays a key role in critically ill patients, due to a dysregulated inflammation characteristic of severe COVID-1921. Therefore, we decided to evaluate HAE patients infected with SARS-CoV-2 in order to describe its influence on their prognosis. Of interest, we compared with patients diagnosed with $\mathrm{HAE}-\mathrm{nC} 1-\mathrm{INH}$, considering that $\mathrm{C} 1-\mathrm{INH}$ is normal in this HAE type.

As a collaborative study, we were able to collect data from 66 patients and no differences were evidenced comparing patients with or without $\mathrm{C} 1$ inhibitor deficiency. This result was not expected since $\mathrm{C} 1-\mathrm{INH}$ is a major regulator of all three pathways of complement activation ${ }^{22}$. Through covalent bond formation with the complement components $\mathrm{C} 1 \mathrm{~s}, \mathrm{C} 1 \mathrm{r}$, MASP1 and MASP2 and reversible binding to $\mathrm{C} 3 \mathrm{a}, \mathrm{C} 1-\mathrm{INH}$ attenuates the consequences of complement activation, including the generation of proinflammatory anaphylatoxins, especially $\mathrm{C} 5 \mathrm{a}$, and the formation of the membrane attack complex (MAC) that leads to cell lysis ${ }^{22,23}$. Coagulation and fibrinolytic pathways are also regulated by $\mathrm{C} 1-\mathrm{INH}$ and it is presumed that the lower $\mathrm{C} 1-\mathrm{INH}$ activity could predispose to more severe SARS-CoV-2 infection ${ }^{24}$. Moreover, C1-INH has been demonstrated to interact with components of the extracellular matrix, leading to the hypothesis that these components concentrate $\mathrm{C} 1-\mathrm{INH}$ at the local site of inflammation in order to regulate complement and contact systems ${ }^{25}$.

The similar course of disease in our patients compared to the general population, can be explained by some findings. Females were the predominant sex in our group as it is described in most HAE casuistries $^{26-30}$. Men have been described with higher severity of COVID-19 in comparison with women 31,32 . The median age observed by us was in the 30 s and it may have influenced the prognosis. Seven HAE patients were older than 60 years of age and this is a risk factor for severe COVID-19. Unfortunately, one 71-year-old patient died from pulmonary complications and multiorgan disfunction related to COVID-19, 28 days after the beginning of symptoms. No additional comorbidity was reported in 
this patient and she was under HAE prophylaxis with danazol. This death accounted for $1.5 \%$ of total cases, less than the mortality reported for general population in Latin American countries ${ }^{33}$. Furthermore, approximately $70 \%$ of our HAE patients had no comorbidities; however, $12 \%$ of them were obese.

Additionally, low $\mathrm{C} 4$ serum levels found in HAE patients might prevent further complement activation and deleterious clinical effects derived from increased complement activity. All these factors could contribute to the better prognosis observed in our population. Different trials inhibiting complement activation, targeting either $\mathrm{C} 3$ or $\mathrm{C} 5$, have been proposed for critically ill patients ${ }^{34}$.

Long term prophylaxis was reported in $52 \%(34 / 66)$ of HAE patients, and attacks occurred in $45.5 \%$ of patients with HAE during SARS-CoV-2 infection. Four patients reported feeling an upper airway obstruction and laryngeal edema, not well characterized; facial edema was associated in two of them. The continued depletion of ACE2 by SARS-CoV- 2 infection increases the extracellular levels of des-Arg9Bradykinin and bradykinin ${ }^{23}$. This effect could contribute to attacks in patients with both HAE-C1-INH and HAE-nC1-INH. In addition, the loss of inhibitory activities of C1-INH would be expected to enhance complement activation together with microvascular injury, leading to worse evolution of SARS-CoV-2 infection ${ }^{25}$.

Androgens, which are able to induce $\mathrm{C} 1$-INH liver production, have been the most accessible therapy in Latin American countries; therefore, it is possible that prophylaxis improved the evolution or severity of COVID-19 in HAE patients. On the other hand, a role of a co-receptor for SARS-CoV-2 infection, transmembrane protease serine 2 (TMPRSS2), was described to be upregulated by androgens in a lungderived cell line model, but not confirmed in physiologic settings ${ }^{35}$. Although this might be a concern in male patients treated with androgens because of the possibility to influence the outcome of COVID-19, none of our 13 male patients had severe clinical manifestations of SARS-CoV-2 infection.

Eight patients were treated with tranexamic acid and no thromboembolism was reported. One patient with $\mathrm{HAE}-\mathrm{nC} 1-\mathrm{INH}$ and no variant identified was hospitalized due to high D-dimer values; however, this finding is described in HAE patients during attacks ${ }^{36}$ and in COVID-19. This patient was not experimenting angioedema symptoms and evolved with no complications except for involvement of $25 \%$ of the lungs during the symptomatic phase.

Long term prophylaxis treatment, to reduce the severity and frequency of HAE episodes, includes infusion of $\mathrm{C} 1-\mathrm{INH}$, which not only reduces kinin-kallikrein activation and BK production, but also might protect against lung injury by inhibiting the cytotoxic activity of extracellular histones ${ }^{37}$. This treatment may improve the outcome of HAE patients with SARS- Cov-2 infection, however, access in Latin America is still limited.

Treatment of acute episodes of HAE includes icatibant, a bradykinin receptor 2 antagonist, or ecallantide, a kallikrein antagonist both of which reduce BK production having a modulatory effect on the "bradykinin storm" described in the pathophysiology of COVID-1938. Some of our patients were treated with icatibant for acute episodes and the clinical response was adequate. 
We evaluated a more representative number of patients with HAE C1-INH and HAE-nC1-INH infected with SARS-CoV-2. The expression of the COVID-19 was not different from the population without HAE, possibly due to the predominance of female and young patients as well as HAE therapy. Our findings suggest that SARS-CoV-2 infection is a trigger for angioedema attacks, however, the prognosis was not influenced, as previously observed by us and others in a much smaller casuistry ${ }^{18,39}$. Fortunately, none of our children had MIS-C; and it is believed that pediatric COVID-19 has a more favorable prognosis ${ }^{40}$. This study exposes the paradox of COVID-19 in HAE patients in real life.

\section{Abbreviations}

ACE2, Angiotensin converting enzyme 2; ARDS, acute respiratory distress syndrome; BK, bradykinin; B1, bradykinin receptor 1; B2, bradykinin receptor 2; C1-INH, C1 inhibitor; COVID-19, coronavirus disease 2019; DABK, des-Arg9-bradykinin; FXII, factor XII; HAE, hereditary angioedema; HAE C1-INH, hereditary angioedema with deficiency of $\mathrm{C} 1$ inhibitor; $\mathrm{HAE} \mathrm{nC1-INH}$, hereditary angioedema with normal $\mathrm{C} 1$ inhibitor; HK, high molecular weight kininogen; IQR, interquartile range; MIS-C, multisystem inflammatory syndrome; SARS-CoV-2, severe acute respiratory syndrome coronavirus 2 .

\section{Declarations}

\section{ACKNOWLEDGEMENTS}

We thank Dr Lina Maria Leiva Panqueva for statistical analysis.

\section{Funding sources: No funding.}

Conflicts of interest/Competing interests (include appropriate disclosures)

Ethics approval: CAAE: 40745220.0.1001.0082

Consent to participate: Patients gave consent and approved to publish the data with no identification. In addition, they contributed for completing the data.

Consent for publication: All authors gave final approval for this version of the manuscript.

\section{Conflict of Interest}

All authors declare that they have no conflicts of interest for this publication.

General conflicts of interest of the authors:

1.Speaker and medical advisor for Takeda; speaker for CSL Behring, Pint Pharma. 2.Speaker, medical advisor and training scholarships for Takeda. Training scholarship for CSL Behring. 4. Speaker for Takeda and CSL Behring. 5.Speaker for: Shire/Takeda, CSL Behring, Novartis and Sanofi. Financial support for advisory board/expert meetings: Shire/Takeda, CSL Behring. 6. Speaker for Takeda, Pint 
Pharma 7. Speaker for: Takeda, CSL Behring. 8. Speaker for CSL Behring, Medical Advisor for Takeda. 9. Speaker and medical advisory for Takeda and Novartis. 10. Fees for presentations, educational and research support from Sanofi, Eurofarma, Novartis,GSK, Phoenix, Stallergenes, and Takeda. Member of the Advisory Board of Takeda. 11. Speaker for Pint Pharma. 12. Speaker for: Takeda. 14. Speaker for Takeda. 15. Speaker for Takeda, Pharming, Biocryst, CSL Behring. Medical Advisor: Pharming and Takeda.16. Speaker for Takeda. 17. Speaker for Takeda. 21. Speaker for Takeda. 22. Speaker for Takeda. 24. Speaker, medical advisor and training scholarships for Takeda. 25. Speaker for Takeda, Bagó, Elea/Phoenix, Glaxo, Roemmer. 26. Speaker for Takeda and Novartis. 28. Speaker and medical advisory for Takeda. 29. Speaker and consultant for Takeda. 31. Speaker and consultant for Shire/Takeda and CSL Behring. Grant of researcher initiative from Shire/Takeda (IST-BRA-00078)

\section{References}

1. Gomide MA, Toledo E, Valle SO, Campos RA, França AT, Gomez NP, Andrade HF Jr, Caballero T, Grumach AS. Hereditary angioedema: quality of life in Brazilian patients. Clinics (Sao Paulo). 2013 Jan;68(1):81-3.

2. Betschel S, Badiou J, Binkley K, Borici-Mazi R, Hébert J, Kanani A, et al. The International/Canadian hereditary angioedema guideline. Allergy Asthma Clin Immunol. 2019;15:72-101.

3. Mendivil J, Murphy R, de la Cruz M, Janssen E, Boysen HB, Jain G, Aygören-Pürsün E, Hirji I, Devercelli G. Clinical characteristics and burden of illness in patients with hereditary angioedema: findings from a multinational patient survey. Orphanet J Rare Dis. 2021 Feb 18;16(1):94-107.

4. Giavina-Bianchi P, Arruda LK, Aun MV, Campos RA, Chong-Neto HJ, Constantino-Silva RN, et al. Brazilian guidelines for hereditary angioedema management - 2017 Update Part 1: definition, classification and diagnosis. Clinics (Sao Paulo). 2018;73:e310.

5. Bork K, Wulff K, Witzke G, Hardt J. Hereditary angioedema with normal C1-INH with versus without specific F12 mutations. Allergy 2015; 70: 1004-1012.

6. Bork K, Machnig T, Wulff K, Witzke G, Prusty S, Hardt J. Clinical features of genetically characterized types of hereditary angioedema with normal $\mathrm{C} 1$ inhibitor: a systematic review of qualitative evidence. Orphanet J Rare Dis. 2020 Oct 15;15(1):289.

7. Zuraw BL. Hereditary angioedema with normal $\mathrm{C} 1$ inhibitor: Four types and counting. J Allergy Clin Immunol. 2018 Mar;141(3):884-885.

8. Wu MA, Bova M, Berra S, Senter R, Parolin D, Caccia S, et al. The central role of endothelium in hereditary angioedema due to C1 inhibitor deficiency. Int Immunopharmacol. 2020;82:106304.

9. Azkur AK, Akdis M, Azkur D, Sokolowska M, van de Veen W, Brüggen MC, et al. Immune response to SARS-CoV-2 and mechanisms of immunopathological changes in COVID-19. Allergy. 2020;75(7):1564-1581.

10. Tay MZ, Poh CM, Rénia L, MacAry PA, Ng LFP. The trinity of COVID-19: immunity, inflammation and intervention. Nat Rev Immunol. 2020;20(6):363-374. 
11. Davanzo GG, Codo AC, Brunetti AS, Boldrini VO, Knittel TL, Monterio LB, et al. SARS-CoV-2 Uses CD4 to Infect T Helper Lymphocytes. medRxiv 2020.09.25.20200329.

12. Mansour, E.; Palma, A.C.; Ulaf, R.G.; Ribeiro, L.C.; Bernardes, A.F.; Nunes, T.A.; Agrela, M.V.; Bombassaro, B.; Monfort-Pires, M.; Camargo, R.L.; et al. Safety and Outcomes Associated with the Pharmacological Inhibition of the Kinin-Kallikrein System in Severe COVID-19. 2021 Feb 16;13(2):309. doi: 10.3390/v13020309. PMID: 33669276; PMCID: PMC7920028.

13. Urwyler P, Moser S, Charitos P, Heijnen IAFM, Rudin M, Sommer G, et al. Treatment of COVID-19 With Conestat Alfa, a Regulator of the Complement, Contact Activation and Kallikrein-Kinin System. Front Immunol. 2020;11:2072;

14. van de Veerdonk FL, Netea MG, van Deuren M, van der Meer JW, de Mast Q, Brüggemann RJ, et al. Kallikrein-kinin blockade in patients with COVID-19 to prevent acute respiratory distress syndrome. eLife. 2020;9:e57555.

15. Roche JA, Roche R. A hypothesized role for dysregulated bradykinin signaling in COVID-19 respiratory complications. FASEB J. 2020;34(6):7265-7269.

16. Kanani AS. A case report of COVID-19 virus infection in a patient with hereditary angioedema. 2020. Available from https://assets.researchsquare.com/files/rs-41261/v1/22000e54-277d-4380-9a06a512a36c170d.pdf Access 16 August 2020.

17. Azmy V, Benson J, Love K, Steele R. Idiopathic nonhistaminergic acquired angioedema in a patient with coronavirus disease 2019. [published online ahead of print, 2020 Jul 1]. Ann Allergy Asthma Immunol. 2020; S1081-1206(20)30447-6.

18. Grumach AS, Goudouris E, Dortas Junior S, Marcelino FC, Alonso MLO, Martins RO, Arpon MA, Valle SOR. COVID-19 affecting hereditary angioedema patients with and without C1 inhibitor deficiency. J Allergy Clin Immunol Pract. 2021 Jan;9(1):508-510.

19. Wu Z, McGoogan JM. Characteristics of and important lessons from the coronavirus disease 2019 (COVID-19) outbreak in China: summary of a report of 72314 cases from the Chinese center for disease control and prevention. 2020 Apr 7;323(13):1239-1242.

20. Lo MW, Kemper C, Woodruff TM. COVID-19: Complement, Coagulation, and Collateral Damage. J Immunol. 2020 Sep 15;205(6):1488-1495. doi: 10.4049/jimmunol.2000644. Epub 2020 Jul 22. PMID: 32699160; PMCID: PMC7484432.

21. Li HH. Pearls and pitfalls in the diagnosis of hereditary angioedema. Allergy Asthma Proc. 2019;40(4):282-284.

22. Jiang, H., Wagner, E., Zhang, H. \& Frank, M. M. Complement 1 inhibitor is a regulator of the alternative complement pathway. J Exp Med 194, 1609-1616, doi:10.1084/jem.194.11.1609 (2001).

23. Thomson TM, Toscano-Guerra E, Casis E, Paciucci R. C1 esterase inhibitor and the contact system in COVID-19. Br J Haematol. 2020 Jun 12:10.1111/bjh.16938.

24. Davis AE, Lu F, Mejia P. C1 inhibitor, a multi-functional serine protease inhibitor. Thromb Haemostasis. 2010;104:886-893. 
25. Xu Y, Liu S, Zhang Y, Zhi Y. Does hereditary angioedema make COVID-19 worse? World Allergy Organ J. 2020 Sep;13(9):100454.

26. Fabiani J, Valle SO, Olivares M, Nieto S, Landeros EH, Ginaca A, Bezrodnik L, Nievas E, Oleastro M, Barrera OM, Gallardo AM, King A, Galindo JR, Carabantes MJ, Craig T, Alfonso MM, Montenegro C, Grumach AS. Improving C1 inhibitor deficiency (type 1 and type 2 hereditary angioedema) in Latin America. J Investig Allergol Clin Immunol. 2014;24(6):445-7.

27. Veronez CL, Mendes AR, Leite CS, Gomes CP, Grumach AS, Pesquero JB; Hereditary Angioedema Brazilian Study Group (GEBRAEH). The Panorama of Primary Angioedema in the Brazilian Population. J Allergy Clin Immunol Pract. 2020:S2213-2198(20)31261-7.

28. Cao 2020.China. One hundred and three patients (including 47 males and 56 females) Orphanet $\mathrm{J}$ Rare Dis.2020; 15: 257.

29. Iwamoto K, Yamamoto B, Ohsawa I, Honda D, Horiuchi T, Tanaka A, Fukunaga A, Maehara J, Yamashita K, Akita T, Hide M. The diagnosis and treatment of hereditary angioedema patients in Japan: A patient reported outcome survey. Allergol Int. 2020 Nov 6:S1323-8930(20)30135-0.

30. Banerji A, Davis KH, Brown TM, Hollis K, Hunter SM, Long J, Jain G, Devercelli G. Patient-reported burden of hereditary angioedema: findings from a patient survey in the United States. Ann Allergy Asthma Immunol. 2020 Jun;124(6):600-607.

31. Guan WJ, Ni ZY, Hu Y, Liang WH, Ou CQ, He JX, et al Clinical Characteristics of Coronavirus Disease 2019 in China. N Engl J Med. 2020;382(18):1708-1720.

32. Chang R, Elhusseiny KM, Yeh YC, Sun WZ. COVID-19 ICU and mechanical ventilation patient characteristics and outcomes-A systematic review and meta-analysis. PLoS One. 2021;16(2):e0246318.

33. Ashktorab H, Pizuomo A, González NAF, Villagrana EDC, Herrera-Solís ME, Cardenas G, ZavalaAlvarez D, Oskrochi G, Awoyemi E, Adeleye F, Dalivand MM, Laiyemo AO, Lee EE, Aduli F, Sherif ZA, Brim H. A Comprehensive Analysis of COVID-19 Impact in Latin America. Res Sq [Preprint]. 2021 Jan 8:rs.3.rs-141245.

34. Risitano AM, Mastellos DC, Huber-Lang M, Yancopoulou D, Garlanda C, Ciceri F, Lambris JD. Complement as a target in COVID-19? Nat Rev Immunol. 2020 Jun;20(6):343-344. Erratum in: Nat Rev Immunol. 2020 Jul;20(7):448.

35. Sharifi N, Ryan CJ. Androgen hazards with COVID-19. Endocr Relat Canc. 2020;27:E1-E3. 71. 36. Reshef, A., Zanichelli, A., Longhurst, H., Relan, A. \& Hack, C. E. Elevated D-dimers in attacks of hereditary angioedema are not associated with increased thrombotic risk. Allergy 2015; 70: 506-513.

37. Wygrecka M, Kosanovic D, Wujak L, Reppe K, Henneke I, Frey H, et al. Antihistone properties of C1 esterase inhibitor protect against lung injury. Am J Respir Crit Care Med. (2017) 196:186-99.

38. Meini S, Zachinelli A, Sbrojavacca R, Luri F, RobertsAT, Suffritti C, Tascini C. Understading the pathophysiology of COVID -19 : Could the contact system be the key? Front Immunol 2020; 11:2014. 
39. Belbézier A, Arnaud M, Boccon-Gibod I, Pelletier F, McAvoy C, Gobert D, Fain O, Du-Thanh A, Launay D, Lupo J, Bouillet L. COVID-19 as a trigger of acute attacks in people with hereditary angioedema. Clin Exp Allergy. 2021 Mar 26. doi: 10.1111/cea.13870. Epub ahead of print. PMID: 33772888.

40. Irfan O, Muttalib F, Tang K, Jiang L, Lassi ZS, Bhutta Z. Clinical characteristics, treatment and outcomes of paediatric COVID-19: a systematic review and meta-analysis. Arch Dis Child. 2021 Feb 16:archdischild-2020-321385. doi: 10.1136/archdischild-2020-321385. Epub ahead of print. PMID: 33593743.

\section{Tables}

Table 1. General characterization of HAE patients with COVID-19 $(n=66)$ 


\begin{tabular}{|c|c|c|c|}
\hline & $\begin{array}{l}\text { HAE C1-INH } \\
(n=53)\end{array}$ & $\begin{array}{l}\text { HAE nC1-INH } \\
(n=13)\end{array}$ & Total \\
\hline Mean age (SD) & $39.6 \pm 15.7$ & $38.9 \pm 13.0$ & $39.5 \pm 15.1$ \\
\hline Age (years) & $N(\%)$ & $\mathrm{N}(\%)$ & \\
\hline $0-9$ & $1(1.5 \%)$ & 0 & $1(1.5 \%)$ \\
\hline $10-19$ & $4(6.1 \%)$ & $1(1.5 \%)$ & $5(7.6 \%)$ \\
\hline $20-29$ & $9(13.6 \%)$ & $1(1.5 \%)$ & $10(15.1 \%)$ \\
\hline $30-39$ & 13 (19.6\%) & $5(7.6 \%)$ & 18 (27.3\%) \\
\hline $40-49$ & 15 (22.7\%) & $3(4.5 \%)$ & $18(27.3 \%)$ \\
\hline $50-59$ & $5(7.6 \%)$ & $2(3.0 \%)$ & $7(10.6 \%)$ \\
\hline $60-69$ & $3(4.5 \%)$ & $1(1.5 \%)$ & $4(6.1 \%)$ \\
\hline$>70$ & $3(4.5 \%)$ & 0 & $3(4.5 \%)$ \\
\hline Sex & N (\%) & $\mathrm{N}(\%)$ & \\
\hline Male & 15 (22.7) & 0 & $15(22.7 \%)$ \\
\hline Female & 38 (57.6) & 13 (19.7) & $51(77.3 \%)$ \\
\hline Prophylaxis & $\mathrm{N}$ & $\mathrm{N}$ & $\mathrm{N}$ \\
\hline No & 25 (37.9) & $7(10.6)$ & 32 (48.5) \\
\hline Androgens & 13 (19.7) & $2(3)$ & 15 (22.7) \\
\hline Tranexamic acid & $7(10.6)$ & $1(1.5)$ & $8(12.1)$ \\
\hline pdC1-INH & $3(4.5)$ & 0 & $3(4.5)$ \\
\hline Others & $5(7.6)$ & $3(4.5)$ & $8(12.1)$ \\
\hline Prophylaxis maintained during COVID-19 & 24 & $6(9.1)$ & 30 \\
\hline Attacks during COVID-19 & $\mathrm{N}(\%)$ & $\mathrm{N}(\%)$ & $\mathrm{N}(\%)$ \\
\hline Yes & $26(39.4)$ & $4(6.1)$ & $30(45.5)$ \\
\hline No & $27(41)$ & $9(13.6)$ & $36(54.5)$ \\
\hline Comorbidities & $\mathrm{N}(\%)$ & $\mathrm{N}(\%)$ & \\
\hline None & $37(56.1)$ & $9(13.6)$ & $46(69.7)$ \\
\hline Obesity & $6(9.1)$ & $2(3.0)$ & $8(12.1)$ \\
\hline Diabetes mellitus & $3(4.5)$ & $1(1.5)$ & $4(6)$ \\
\hline
\end{tabular}




\begin{tabular}{|llll|} 
Arterial hypertension & $3(4.5)$ & 0 & $3(4.5)$ \\
\hline Others (Neoplasia, Autoimmunity) & $4(6,1)$ & $1(1,5)$ & $5(7.6)$ \\
\hline Period with symptomatology & & & \\
Median days (IQR) & $11(7-15)$ & $10(3-15)$ & - \\
\hline Hospitalization N(\%) & $6(9.1)$ & $2(3.0)$ & $8(12.1)$ \\
Evolution & $\mathrm{N}(\%)$ & $\mathrm{N}(\%)$ & \\
Cure & $49(74,2)$ & $12(18,2)$ & $61(92.4)$ \\
Sequelae & $3(4,5)$ & $1(1,5)$ & $4(6)$ \\
Deceased & $1(1,5)$ & 0 & $1(1.5)$ \\
\hline
\end{tabular}

SD, Standard deviation; pdC1-INH, plasma derived C1 inhibitor; IQR Interquantile range Table 2. Therapy instituted in HAE patients infected with SARS-CoV-2

\begin{tabular}{|lllll|}
\hline Treatment & Yes & \multicolumn{3}{c|}{ No } \\
& $\mathrm{N}$ & $\%$ & $\mathrm{~N}$ & $\%$ \\
\hline Analgesics & 35 & 57.6 & 31 & 42.4 \\
Non steroidal Anti-inflammatories & 7 & 10.6 & 59 & 89.4 \\
Anticoagulant & 8 & 12.1 & 58 & 87.9 \\
Steroids & 13 & 19.7 & 53 & 80.3 \\
Antibiotics & 15 & 22.7 & 51 & 77.3 \\
C1 inhibitor & 2 & 3 & 64 & 97 \\
\hline Convalescent plasma & 1 & 1.5 & 65 & 98.5 \\
Others & 17 & 25.8 & 49 & 74.2 \\
\hline
\end{tabular}

\section{Supplementary Files}

This is a list of supplementary files associated with this preprint. Click to download.

- COIJoCl.docx 